
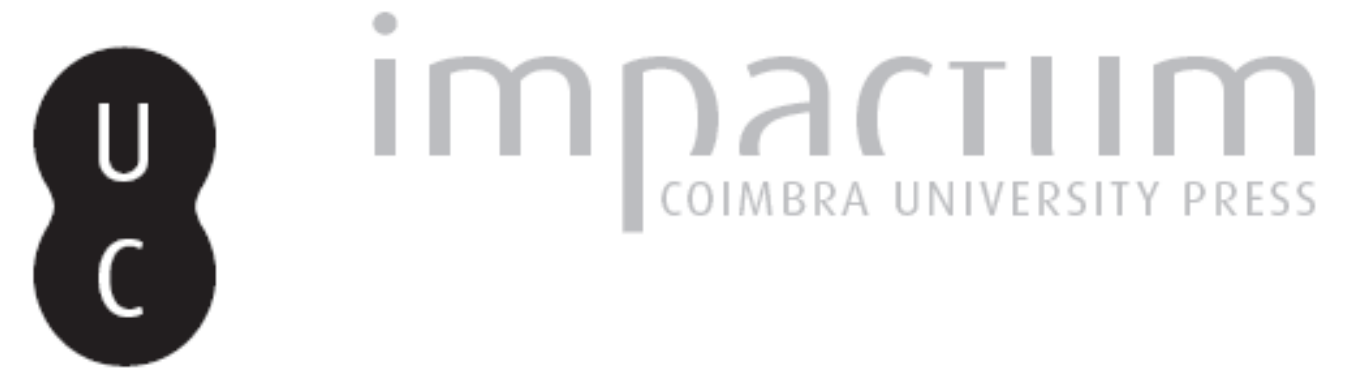

Estado pós-nacional e ampliação da liberdade do cidadão na Europa contemporânea

Autor(es): $\quad$ Gomes, Daniel Machado

Publicado por: Universidade Católica de Petrópolis

URL persistente:

URI:http://hdl.handle.net/10316.2/33911

DOI:

DOI:http://dx.doi.org/10.14195/2175-0947_1-1_11

Accessed : $\quad$ 26-Apr-2023 14:00:37

A navegação consulta e descarregamento dos títulos inseridos nas Bibliotecas Digitais UC Digitalis, UC Pombalina e UC Impactum, pressupõem a aceitação plena e sem reservas dos Termos e Condições de Uso destas Bibliotecas Digitais, disponíveis em https://digitalis.uc.pt/pt-pt/termos.

Conforme exposto nos referidos Termos e Condições de Uso, o descarregamento de títulos de acesso restrito requer uma licença válida de autorização devendo o utilizador aceder ao(s) documento(s) a partir de um endereço de IP da instituição detentora da supramencionada licença.

Ao utilizador é apenas permitido o descarregamento para uso pessoal, pelo que o emprego do(s) título(s) descarregado(s) para outro fim, designadamente comercial, carece de autorização do respetivo autor ou editor da obra.

Na medida em que todas as obras da UC Digitalis se encontram protegidas pelo Código do Direito de Autor e Direitos Conexos e demais legislação aplicável, toda a cópia, parcial ou total, deste documento, nos casos em que é legalmente admitida, deverá conter ou fazer-se acompanhar por este aviso. 

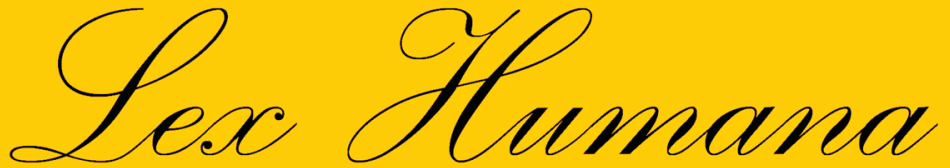

Revista do Programa de Pós-Graduação em Direito da UCP

ISSN(e) 2175-0947

Universidade Católica de Petrópolis Rua Benjamin Constant, 213 - Petrópolis - Centro CEP 25610-130

Tel: (24) 2244-4000 E-mail: lexhumana@ucp.br 


\section{ESTADO PÓS-NACIONAL E AMPLIAÇÃO DA LIBERDADE DO CIDADÃO NA EUROPA CONTEMPORÂNEA}

Daniel Machado Gomes

« Je ne suis "libre" ni d'échapper au sort de ma classe, de ma nation, de ma famille, ni même d'édifier ma puissance ou ma fortune, ni de vaincre mes appétits les plus insignifiants ou mes habitudes ». ${ }^{1}$

Se fora do organismo político, qualquer que seja, não há significado nem dignidade para o homem, como defende Hannah Arendt, é preciso que esta vivência política não se converta em totalitarismo, garantindo a liberdade e a pluralidade de valores na sociedade. O Estado, como organização política, deve estar estruturado de maneira a tutelar a liberdade do homem. Hoje, vê-se um enfraquecimento do modelo do Estado-nação. Por um lado, há desafios que ultrapassam a possibilidade de uma solução nacional, como nas áreas da segurança e da economia. Por outro, há os anseios a uma liberdade que desconheça fronteiras territoriais e se materialize através de uma cidadania transnacional. Ganha revelo, assim, a idéia de um novo modo de organização política desvinculada do nacionalismo, capaz de potencializar a liberdade - o Estado pós-nacional.

O espaço político apresenta-se sob variadas maneiras no decorrer da História. Nações e Estados são contingenciais, e a congruência dos dois conceitos não é um imperativo necessário, como pretende o nacionalismo. A crise do Estado-nação evidencia-se pela tendência de formação de blocos políticos e econômicos, destinados a cuidar de matérias que o Estado nacional já não pode enfrentar isoladamente - direitos humanos, crimes contra a ordem econômica, tráfico de entorpecentes e pessoas ou mesmo matérias concernentes ao comércio, subsídios agrícolas, ou às telecomunicações. A "questão nacional", como chamada pelos marxistas, refere-se à intersecção de política, tecnologia e fatores sociais. A nação, um dos elementos formadores do Estado, pela teoria clássica, o é de um tipo de Estado, ligado a um estágio específico do desenvolvimento econômico. $\mathrm{Na}$ 1 SARTRE, Jean Paul._L'Etre et le Néant, coll. Tel, éd. Gallimard, pp. 538539. 
era do pós-industrialismo, com um capitalismo globalizado, o Estado assume uma feição pós-nacional. A União Européia é o mais bem sucedido exemplo de cooperação e integração entre Estados. Na visão de Jean Marc Ferry, insinua-se hoje um Estado europeu. Para o autor, a unificação da moeda no espaço europeu, a integração dos sistemas militares, a cooperação judiciária e policial, uma certa coesão quanto à política externa assinalam mais do que uma união política européia, indicando a emergência de um Estado, em moldes diversos dos Estados nacionais, cujo processo de formação é igualmente diverso.

O anseio a uma liberdade, materializável através de uma cidadania transnacional, é próprio do homem modular. O homem modular - como Gellner chama - é capaz de combinar-se a associações e instituições, sem que estas lhe sejam totais, porém estabelecendo múltiplas ligações. Ele pode desligar-se de uma associação, sem ser acusado de traição, de apostasia, porque é altamente variável em suas atividades, executando tarefas diversificadas num mesmo código cultural. A mobilidade do homem modular manifesta-se através da homogeneidade cultural, da capacidade de comunicação livre de contexto, da padronização da expressão e da compreensão, que, paradoxalmente, contribui tanto para formação da sociedade nacionalista, quanto da sociedade civil. Por isso, as mesmas forças que produziram a modularidade, produziram o nacionalismo, ambos opondo-se ao Estado absolutista barroco. Para Gellner, essas duas forças - modularidade (individualismo) e nacionalismo - entraram em colisão, porque o liberalismo do homem modular, levado às últimas conseqüências, não pode suportar o culto à comunidade. A aversão do homem modular a imposições sociais faz com que ele aspire pela condição de cidadão cosmopolita. A nacionalidade, determinante de status jurídico de cidadão, é opressora e totalitária para um homem que decide as associações a que pertence. A condição jurídica do homem modular nasce da sua humanidade. A cidadania não pode estar subordinada a um território onde se nasça, nem a uma linhagem à qual se pertença, mas deve decorrer da própria condição de ser humano, transbordando assim, as fronteiras do nacional.

A idéia de um Estado pós-nacional é passível de analogia com a visão kantiana da Paz Perpétua. Em ambos há a postulação de conquista da liberdade, através da criação de uma estrutura jurídica que não é o direito interno, tampouco o direito internacional, mas um direito cosmopolita. Kant não propõe um super-Estado, mas sim uma associação de Estados, evitando o problema da soberania estatal. Kant pretende a transplantação do 
ideário iluminista da lei como geradora de liberdade individual, e do Direito conquanto instrumento pacificador das relações entre os povos, por força do desenvolvimento de uma associação dos Estados nacionais. O Estado pós-nacional possui exatamente essa leveza, coexistindo com a estrutura nacional, superando-a porém, em alguns aspectos, mas sem a pretensão de ser uma força totalizante e absoluta. O substrato ético da teoria kantiana da paz perpétua é o mesmo de um Estado pós-nacional, pois a condição de cosmopolita deve-se ao fato de que todos os homens possuem o direito de entrar em sociedade com seus semelhantes, em virtude da posse comum originária de toda a superfície da terra.

A implementação de um modo de organização política como o Estado pós-nacional é a implementação de uma liberdade internacionalizada, que desconhece o fracionamento territorial, materializando-se na cidadania cosmopolita cuja fonte é o próprio humanismo. Estruturar o funcionamento de uma ordem política dessa natureza é um desafio para a ciência jurídica, que requer respostas quanto à sua operacionalização. Para tanto, é preciso delimitar alguns conceitos que se referem ao novo modelo de organização política: a começar pela auto-certificação do conceito de estado pós-nacional; passando pela aplicação desse conceito à Europa unificada de hoje; para, finalmente, especular sobre os efeitos de uma ordem política pós-nacional na cidadania.

\section{Como entender a expressão Estado Pós-Nacional?}

Habermas, em estudos sobre a modernidade e a pós-modernidade, refere-se ao prefixo pós como prefixo de negação do termo subseqüente, assim a pós-modernidade deve ser entendida como a negação da modernidade. Por Estado pós-nacional, portanto, deve-se entender, utilizando-se a explicação de Habermas, a negação do elemento nacional como um dos componentes do ente público. Essa idéia apresenta dois problemas correlatos: a exata compreensão do significado dessa negação, e o modo de estruturação jurídica dessa nova forma de Estado.

A negação ao elemento nacional não deve ser entendida como negação da existência da nação, enquanto objeto em si mesmo. Ao contrário, o Estado pós-nacional não se preocupa em discutir a espontaneidade da nação, antes desvincula-se dela, reconhecendo a maior pluralidade possível de nações dentro da sua estrutura. Não se trata da negação à existência da nação ou da nacionalidade, mas do esvaziamento do conteúdo jurídico das 
categorias de nacional ou estrangeiro, que passam a representar o mesmo em face do Estado. Desse modo, a cidadania independe da nacionalidade no Estado pós-nacional. A condição jurídica de todos os homens está igualada, e a idéia de nação fica desprovida de qualquer significado jurídico, reduzida a um elemento cultural, na pluralidade da vida pública.

A estruturação desse Estado dá-se pela associação das nações, convivendo pacificamente, sob um espaço político comum, onde os fundamentos sejam a democracia e um direito cosmopolita, que se aplique a todos os povos. Isso implica na necessidade de um poder centralizador para impor as normas jurídicas, o que colide com a teoria clássica da soberania nacional, soberania que tem sua máxima expressão na nação. Surge então a importância de se analisar a possibilidade de um soberania compartilhada ou a legitimidade de uma transferência da soberania nacional ao ente supranacional.

Tanto uma cidadania cosmopolita, quanto uma organização política supra-nacional demandam um direito renovado, e fundado em bases comuns a todos os povos. A superação da nação não significa a padronização, a planificação totalitária da cultura, significa sim a co-existência das diferentes expressões culturais num mesmo espaço político, verdadeiramente democrático, onde todos possuam a mesma condição perante o ente público. Trata-se, naturalmente, de um modelo ideal, e o presente artigo pretende analisar como essa estrutura jurídica seria mais condizente com o nosso tempo, e ainda as possibilidades de se considerar a Europa como um Estado pós-nacional.

2. É possível uma organização política que não seja o Estado-nação?

Na nação reside o substrato da soberania do Estado, segundo a visão rousseauniana do contrato social. Nessa perspectiva, ela deve ser entendida como um a priori, um conceito pré-político que antecede a formação do Estado. Surge então, a indagação sobre a forma (no sentido aristotélico) da nação, ou seja, aquilo que faz com que uma nação seja uma nação. A partir da resposta a essa indagação pode-se estabelecer a relação entre nação e Estado, para então determinar-se a possibilidade de uma estruturação política desvinculada desse conceito.

Dois posicionamentos se apresentam em relação à nação. O primeiro une teóricos marxistas e liberais, para quem a nação é uma construção artificial, não podendo, portanto, ser conhecida senão a posteriori, depois de 
formado o Estado. Benedict Anderson, marxista que dedicou-se ao estudo da questão nacional, vê a nação como uma comunidade imaginária, uma criação política para legitimar o Estado e a empresa industrial. O segundo posicionamento é esposado por teóricos de caráter contratualista, que vêem a nação como um grupo aspirando, naturalmente, por independência, e existindo em si mesmo. De acordo com essa visão, a nação, através da constituição, transfere a soberania ao Estado, conferindo-lhe legitimidade para o exercício do poder. Nesse segundo grupo de teóricos, sobressai a figura de Ernest Renan, que dedicou-se a definir o conceito de nação. Renan, em conferência proferida na Sorbonne, menciona a teoria francesa do direito das nações (de cunho liberalista) e a teoria alemã organicista (baseada no elemento étnico), concluindo por uma concepção eletiva de nação, adotando o argumento voluntarista, segundo o qual, a nação é uma escolha incessantemente renovada de seus membros. ${ }^{2}$

Durante o século $\mathrm{XX}$, um dos autores que mais dedicou-se à análise da relação entre nação e Estado foi Ernest Gellner. Ele analisou o fenômeno político moderno sob a perspectiva do que chamou nacionalismo, termo que utiliza para designar a necessária congruência entre nação e Estado. A política, segundo ele, necessita de uma justificação de autoridade, uma legitimação ${ }^{3}$ que nas sociedades industriais dá-se pela capacidade de produzir e conservar uma riqueza generalizada, assim como, por uma cultura comum entre governantes e governados. A teoria de Gellner sobre o nacionalismo passa exatamente pela satisfação dessas condições. Ele critica a idéia de que o nacionalismo seja um fenômeno natural, demonstrando que ele não se origina das nações, sendo muitas vezes a origem delas. $\mathrm{O}$ nacionalismo é o substrato legitimador do Estado moderno, determinando um sentimento de lealdade e identificação da população em relação às unidades políticas. A nação, portanto, normalmente interpretada como fruto de um protonacionalismo popular tendente à formação de um Estado, nada mais é do que uma criação do próprio Estado. Basta pensar que, antes da alfabetização generalizada na Europa, não havia nenhuma língua nacional ${ }^{4}$. A consolidação da educação serviu também para a consolidação de uma divisão do trabalho, que é peculiar à industrialização e ao Estado nacional.

Uma vez apresentadas as correntes teóricas que se referem à questão

2 Idem, p. 61.

3 GELLNER, Ernest. Nacionalismo e democracia. p. 44

4 HOBSBAWM, Eric. Nações e Nacionalismo. p.69 
nacional, dá-se o desdobramento das interpretações supramencionadas quanto à soberania, a qualidade do poder do Estado. Para a teoria clássica, a nação é o substrato da soberania entendida como um poder uno, indivisível, imprescritível e inalienável. Cada nação deve corresponder a um Estado soberano na visão de Mazzinni, intelectual italiano responsável pelo embasamento teórico do Rissurgimento. Dessa maneira, atingindo-se a soberania do Estado atinge-se diretamente a nação, pois a qualidade de soberania depende do elemento nacional. Partindo-se, portanto, da idéia de que a nação não é um referencial a priori, a soberania, enquanto qualidade intocável, fica fragilizada, ou melhor, pode ser repensada para além das fronteiras nacionais.

O Estado moderno sustenta-se na relação com a nação, mas o enfraquecimento desta, da função e da idéia que ela encarnava é um fenômeno atual ${ }^{5}$. Partindo-se da não congruência entre esses dois conceitos, surge a possibilidade de um modo de organização política diverso do Estado nacional. Na medida em que essa nova forma de estar na vida pública desvincula o poder da nação, insinua-se o Estado pós-nacional, no qual o substrato de legitimidade é o homem pelo simples fato de ser homem.

3. Em que medida a União Européia pode ser considerada como um Estado?

A União Européia possui uma estrutura executiva, legislativa, e jurisdicional, através de instituições comunitárias, cujas normas e decisões têm aplicação imediata nos Estados membros. Trata-se de uma estrutura supranacional, onde o direito vigente não é internacional, mas comunitário. A definição de supranacionalidade é controvertida, apesar disso, a integração européia encontra-se sobre ela estruturada. O significado da supranacionalidade pode ser entendido de duas maneiras: como uma soberania compartilhada, e como uma transferência da soberania dos Estados membros.

Jean Marc Ferry analisa a Europa unificada como um Estado de povos unidos, o que na sua leitura configura a maior revolução política da história contemporânea. ${ }^{6}$ Trata-se de uma nova forma de Estado, um Estado cosmopolita, pós-nacional, com uma estrutura jurídica de base que 
estabelece uma certa liberdade para relações jurídicas de ordem privada contratar, residir, trabalhar - e com normas de direito público. Para ele, a União Européia instituiu um descompasso entre a comunidade moral e a comunidade legal, citando os termos empregados pelo pensador americano Michael Walzer. Por comunidade moral entenda-se a comunidade de crenças, valores, idéias de indivíduos que compartilham um mesmo espaço cultural, num mesmo momento histórico. Comunidade legal deve ser entendida como a aplicabilidade de políticas públicas oponíveis a uma coletividade sob mesma jurisdição. O Estado tradicionalmente apresenta-se como a união dessas duas formas de comunidade, embora, cada vez mais, elas dissociemse nas sociedades atuais. Segundo Ferry, esse rompimento é uma tendência no interior das nações ocidentais, que valorizam o multiculturalismo. Assim, surge a crise da idéia de que comunidade moral e legal devam, necessariamente, caminhar juntas.

É possível porém, analisar a União Européia como um organismo sui generis, que altera o funcionamento dos velhos Estados europeus, mas não lhes retira a soberania. Jellinek serve de embasamento a este posicionamento, pois defende que embora o Estado precise de poder para desempenhar funções, este poder não é, necessariamente, soberano (Estado medieval, por exemplo). Para ele, a soberania surgiu conjuntamente com o Estado moderno, para justificar a reunião de poderes nas mão dos monarcas, não se confundindo, portanto, a soberania com os poderes do Estado. Na visão de Jellinek, o Estado sobrevive, mesmo se integrado a uma estrutura supranacional, que exerça poderes peculiarmente estatais.

Não é simples determinar uma solução à questão do Estado Europeu. A matéria, todavia, merece ser apreciada sob uma ótica renovada, pois tratase de um novo paradigma de Estado, capaz de conviver com um alto grau de autonomia das nações que o compõe. A supranacionalidade difere-se da federação e da confederação, requer novos e criativos métodos para análise. O Estado Europeu é um Estado pós-nacional, na medida em que supera o elemento nacional, concedendo um novo tipo de cidadania, diferente daquela vinculada à nação. Por outro lado, não é uma organização centralizadora, nem apóia-se nos mesmos elementos vinculantes do tradicional Estado nacional, ele representa a morte do Estado no sentido universalizante de até então. O Estado Europeu destrói o universalizante e o absoluto, e abre-se à realidade do pluralismo da própria Europa.

4. Uma organização política do tipo "Estado" separada do elemento 
nacional é um fator de ampliação da liberdade individual?

Estado pós-nacional é um modo de organização política que amplia a liberdade individual, na medida em que é um modo de organização da vida pública onde se privilegia a pluralidade. Isso ocorre porque nele a condição de cidadão está dissociada da nacionalidade, enquanto no Estado moderno, a fronteira territorial é também uma fronteira ao exercício da liberdade. Tratase de uma outra concepção de democracia, na qual os indivíduos apresentamse como sujeitos de direitos, independentemente das qualificações.

A cidadania pode ser entendida segundo duas orientações, ambas com origem no século XVIII. Para uns, sob uma perspectiva liberal, a cidadania representa sobretudo a liberdade individual e a propriedade privada. Segundo essa visão, a cidadania é uma vitória da burguesia sobre o Ancién Regime, sem preocupação com a socialização desta conquista. Outros vêem a cidadania, sob uma ótima mais progressista, pois analisam o homem no meio social e econômico, enfatizando não apenas a importância da liberdade, mas também da igualdade. É basicamente a visão da III República, que se manifesta através da laicização do Estado, e da universalização do estudo, com a alfabetização em massa. Na visão de Dollinger, a cidadania tem caráter adicional, político, que faculta às pessoas certos direitos políticos. ${ }^{7}$ Para Hannah Arendt cidadania é o direito a ter direitos, cujo exercício é o meio criador do espaço público que torna possível a liberdade. Cidadania, enfim, é uma prerrogativa de liberdade que envolve aquisição e gozo de direitos de todas as ordens - direitos civis, individuais, sociais e políticos.

Não se deve, contudo, interpretar essa conquista liberal meramente como um meio para se alcançar um modelo econômico. A razão de ser desse novo Estado é a autonomia democrática, que exige uma economia igualmente democrática, onde compartilhem-se os bens livremente entre os povos. Um Estado pós-nacional amplia a liberdade individual por ter como substrato liberdade, especialmente no que tange à circulação. Ele não se afirma apelando ao dever cívico, à lealdade, à identidade, à dívida de pertencer a um grupo determinado. Ao contrário, a cultura do pós-nacional é a cultura do pluralismo por excelência, é o meio político da diversidade, onde o fator que conta é a liberdade do indivíduo e sua opção de escolha. Nada, além da própria escolha, pode ser determinante da condição de sujeito de direitos em face do ente político ou de qualquer outro ente.

$\mathrm{Na}$ era do Estado-nação, a prerrogativa da cidadania está interligada 
à condição de nacional, pois a nação é o fundamento desta forma de Estado, ela constitui um fato natural anterior à cidadania. O Estado pós-nacional, ao contrário, é uma forma de organização que dissocia a cidadania da nacionalidade, e esvazia o conteúdo jurídico desta para conceder a todos a condição de cidadão pelo simples fato de pertencerem à condição humana. A base desta nova cidadania está na erosão do elemento nacional e extensão das vantagens individuais e sociais, pois um dos princípios norteadores do Estado pós-nacional é a livre circulação, seja ela de bens, seja de pessoas. Essa é a característica mais visível dessa nova forma de Estado, que relaciona-se com o grande mercado global e as exigências de mobilidade e de uma economia mundializada.

7. O Estado pós-nacional pode ser entendido como o modelo kantiano de associação de Estados da Paz Perpétua?

Kant escreveu a A Paz Perpétua sob a forma de um tratado internacional. Para tanto, baseou-se em quatro pontos principais: 1) os Estados, no que concerne às suas relações externas, vivem num estado jurídico provisório; 2) o estado de natureza é um estado de guerra, portanto injusto; 3) por ser injusto, os Estados devem fundar uma federação de Estados, uma espécie de contrato social; 4) essa federação é uma associação de Estados e não um superestado. Para se alcançar esse estado de paz, Kant apresenta três artigos definitivos: 1) a constituição de qualquer Estado deve ser republicana; 2) o direito internacional deve fundar-se numa federação de Estados livres; o direito cosmopolita deve ser limitado às condições de uma hospitalidade universal. Interessa-nos o terceiro artigo definitivo quando o autor trata do direito cosmopolita. Passemos agora a analisar a proposta de Kant em face do ideário de um Estado pós-nacional.

A primeira objeção à analogia com a proposta kantiana é fato de Kant não propor a formação de um Estado, mas de uma associação de Estados. Preliminarmente, é preciso compreender o conceito de Estado, segundo a visão kantiana. O Estado para Kant é uma criação através da qual o povo deixa sua liberdade externa para retoma-la novamente como membro de um corpo comum, ou seja, como membros do povo enquanto Estado. ${ }^{8}$ Nesse sentido, o Estado kantiano é um Estado liberal, cujo objetivo é permitir o desenvolvimento da liberdade individual. Portanto, mesmo o que 
Kant chama de associação de Estados pode ainda ser interpretado como um Estado, visto que também reúne prerrogativas de soberania, especialmente no que concerne ao direito cosmopolita. Em sentido contrário, vem o fato de Kant referir-se à aplicação de um direito internacional, concomitantemente, a um direito cosmopolita, entre os povos. Quanto a isso, a proposta de um Estado pós-nacional vai além da idéia kantiana, pois extingue a aplicação das normas internacionais entre as nações que o compõe. Não se trata, pois, de uma federação como nós conhecemos, tampouco de um organismo nacional, mas de uma estrutura intermediária, que pode ser considerada como a morte do Estado, se a premissa da análise for o Estado tal qual se apresenta atualmente. Nesse caso, trata-se sim da morte do Estado. Todavia, morte aqui não significa o fim do Estado, mas simplesmente a morte da possibilidade de uma universalização absoluta de poder soberano através da divisão de atribuições e competências com células políticas menores. $\mathrm{O}$ Estado pós-nacional é o ente soberano tão somente quanto à concretização da sua finalidade: a liberdade individual, que se dá através de uma cidadania supranacional de todos os homens, independentemente do povo a que pertença.

O direito cosmopolita kantiano é a prerrogativa do estrangeiro não ser tratado com hostilidade no território de um outro Estado. A proposta pósnacional é uma concretização dessa prerrogativa, por extinguir as categorias jurídicas de estrangeiro e de nacional. Segundo essa ótica, todos são de todos os lugares, o que se justifica na premissa kantiana do direito de todos os homens de entrar em sociedade com seus semelhantes, em virtude da posse comum originária de toda a superfície da terra. O direito cosmopolita, portanto, se materializa no constituição de uma cidadania supranacional, regida por um ente estatal pós-nacional.

A filosofia política kantiana baseia-se na liberdade individual, finalidade do Estado pós-nacional, que promove a paz mundial, em conseqüência de um sentimento de fraternidade independente das diferenças culturais, da nacionalidade. A analogia entre o Estado pós-nacional e a associação de Estados kantiana funda-se ainda, no fato de ambos preverem uma união de povos estruturada em um princípio comum, regida por um direito que não possa ser definido como internacional, nem como nacional - o direito cosmopolita. O Estado pós-nacional porém, vai além da idéia kantiana na medida em que supera as qualificações de nacional e estrangeiro, rompendo a necessidade do direito internacional, embora não impeça a coexistência de autoregulação dos povos que o compõe, desde que esta não 
implique limitação à liberdade dos demais membros do ente público.

8. Referências Bibliográficas

ARENDT, Hannah. Les Origines du Totalitarisme. Paris: Éditions du Seuil, 1972.

Qu'est-ce que La Philosophie de l'Existence? Paris: Payot \& Rivages, 2002.

BOBBIO, Norberto. Direito e Estado no Pensamento de Emanuel Kant. Trad. de Alfredo Fait. Brasília: Universidade de Brasília, 1984.

FERRY, Jean-Marc. La Question de l'État Européen. Paris: Gallimard, 2000.

. L'Allocation Universelle: pour un revenu de citoyenneté. Paris: Cerf, 1995.

. Espaces Publics, Traditions, et Communautées. Paris: CNRS, 2001.

. L'École au défi de l'Europe: Médias, Éducation, et Citoyenneté Postnational. Bruxelles: Uniniversité de Bruxelles, 2003

GELLNER, Ernest. Nations and Nationalism. Ithaca: Cornell University Press, 1983.

Condições da Liberdade: a Sociedade Civil e seus rivais. Trad. de Lugy Magalhães. Rio de janeiro: Jorge Zahar, 1996.

. Nacionalismo e Democracia. Trad. de Vamireh Chacon e outros. Brasília: universidade de Brasília, 1981.

KANT, Immanuel. La Paz Perpetua. Buenos Aires: ESPASA, 1946.

MAGNETTE, Paul. La grande Europe, Bruxelles, Editions de 1'Université de Bruxelles,

MELLO, Celso D. De Albuquerque. Anuario Direito e Globalização: a 
Soberania. Rio de Janeiro: Renovar, 2004.

Arquivos de Direitos Humanos. 2000 4V.

Curso de Direito Internacional Público. 15 ed. 2004. 2V. 